\title{
Congenital malformations in twins in England and Wales
}

\author{
P E Doyle, V Beral, B Botting, C J Wale
}

\begin{abstract}
Study objective-The aim was to compare congenital malformation rates in twin births with those in singleton births.

Design-The study was an analysis of malformation rates in singleton and twin births using data from the Office of Population Censuses and Survey's Congenital Malformation Notification Scheme.
\end{abstract}

Setting-This was a national survey of births in England and Wales in 1979-1980 and 1982-1985.

Participants-The data comprised 95510 reported malformations in 3.7 million singleton births, and 1925 reported malformations in 76000 twin births.

Measurements and main results-Twin malformation ratios were calculated using maternal age specific singleton rates as standard. In comparison with singleton births, twins have significantly higher reported frequencies of indeterminate sex and pseudohermaphroditism; anencephaly; patent ductus arteriosis; exomphalos; hydrocephalus; anomalies of the umbilical vessels; atresia or stenosis of the large intestine or anus; and tracheo-oesophageal fistula, atresia or stenosis. Twins also have significant reported deficits of polydactyly and syndactyly; congenital dislocation of the hip; anomalies of the tongue, branchial cleft and auricular sinus; post-anal dimple; and Down's syndrome.

Conclusions-Several major malformations were significantly more common in twins than in singletons. The excess of indeterminate sex and pseudohermaphroditism has not been described before and may be analogous to freemartinism in cattle. Most of the conditions less common in twins are minor, and the reported deficits may be due to underascertainment of the less serious conditions in twins. Down's syndrome is an exception, and the deficit may well be real.

One in every 100 maternities in England and Wales results in twins. ${ }^{12}$ Malformations of the central nervous system, alimentary system, and cardivascular system have been reported to occur more commonly in twins that in singleton births. ${ }^{3-9}$ Many of these reports have, however, been based on small numbers of twins with specific malformations. We report here on malformation rates in twin and singleton births notified to the Office of Population Censuses and
Surveys (OPCS) for the years 1979-1980 and 1982-1985. The data cover a period during which there were 3.7 million births of which 76000 were twins.

\section{Methods}

OPCS data on notifications of congenital malformations and of birth registrations in England and Wales were analysed for the years 1979-1980 and $1982-1985 .{ }^{10}$ Some variables collected through birth registration in 1981 were partially coded (because of industrial action by the registrars of births) and so all data for 1981 are excluded. In the OPCS congenital malformation notification scheme, a standard record form (SD56) is used by District Health Authorities to notify details of each malformed livebirth or stillbirth. ${ }^{11}$ Notification to the District Health Authorities is voluntary by midwives or doctors. Only malformations detected at birth or within seven days of birth are included. Malformations, as described on the form SD56, are coded by trained staff according to the 9th revision of the International Classification of Diseases (ICD). ${ }^{12}$ Each child can have as many as eight different malformations coded. The diagnostic conditions selected for analysis here are essentially those used by OPCS in their routine publications on malformations. Down's syndrome and other chromosomal anomalies are, however, considered separately rather than as a single group; indeterminate sex and pseudohermaphroditism are separated from anomalies of the female genitalia; transposition of the great vessels is separated from other septal defects; and since cleft lip and cleft palate were not accurately distinguished in notifications, cleft lip and/or palate were considered as a single group (Appendix). The OPCS data include information on whether the child is from a single, twin or higher order birth. The sex of the cotwin is not recorded, and the congenital malformation record is not linked to the corresponding birth record.

There were 1652 triplet or higher order births in the time period considered, among whom 33 malformations were reported. Because of the small numbers of such births, these data were excluded from the analyses presented here.

Malformations rates for singletons were calculated as the number of malformations reported divided by the number of births. The same individual is included in more than one malformation rate if more than one malformation is reported. Rates in twins were adjusted for maternal age by indirect standardization, using the singleton rates as the standard. Each malformation rate for twins was obtained by 
applying the singleton maternal age specific malformation rate for each five year maternal age group to the twin births "at risk" in the same maternal age group, summing the observed and expected number of cases over all maternal ages and multiplying the observed:expected ratio by the rate for the same malformation in singletons.

The observed:expected ratio is referred to as the "malformation ratio". Bailar tables were used to calculate confidence limits around each malformation ratio.

Equations presented in Breslow and Day ${ }^{13}$ were used to test the significance of the difference between each standardised malformation rate for twins and the rate for the same malformation among singletons.

\section{Results}

The number of births and malformations reported in twins and singletons are shown in table I. Malformations were reported in 80027 infants, of whom 1491 were twins. The proportion of twin babies with one or more defects was lower than that in singleton babies $(p<0.05)$. However the malformation rate per 10000 births did not suffer significantly between twin and singleton births since more than one defect in the same infant was reported more frequently in twins than singletons $(19 \% v 15 \%$; $\mathrm{p}<0.001$ ).

Table I Notification of births and malformations in twins and singletons. England and Wales, 1979-1980 and 1982-85

\begin{tabular}{lcc}
\hline & Twins & Singletons \\
\hline Total births & 75844 & 3789821
\end{tabular}

\begin{tabular}{|c|c|c|}
\hline \multicolumn{3}{|c|}{ Births with one or more malformation } \\
\hline $\begin{array}{l}\text { Number } \\
\text { Rate per } 10000 \text { births }\end{array}$ & $\begin{array}{l}1491 \\
196 \cdot 6\end{array}$ & $\begin{array}{l}78536 \\
207 \cdot 2\end{array}$ \\
\hline $\begin{array}{l}\text { Total malformations } \\
\text { Number } \\
\text { Rate per } 10000 \text { births }\end{array}$ & $\begin{array}{l}1925 \\
253 \cdot 8\end{array}$ & $\begin{array}{r}95510 \\
252 \cdot 0\end{array}$ \\
\hline $\begin{array}{c}\text { Number of malformation } \\
1 \\
2 \\
3 \\
4+\end{array}$ & $\begin{array}{l}\text { birth } \\
1213(81 \%) \\
202(14 \%) \\
43(3 \%) \\
33(2 \%)\end{array}$ & $\begin{array}{c}66862(85 \%) \\
8786(11 \%) \\
1667(2 \%) \\
1221(2 \%)\end{array}$ \\
\hline
\end{tabular}

Standardised prevalence rates and malformation ratios in twins compared to singletons are shown in table II for malformations grouped according to anatomical site and for selected specific malformations within each group. Ratios significantly greater than 1.0 were found for the grouped malformations of the central nervous system, alimentary canal system, cardiovascular system, musculoskeletal system (other than limbs) and for those classified as "other" (see Appendix for the diagnoses included in these groups). The ratios for grouped malformations of the limbs, of skin and integument, and of chromosomal origin were significantly less than $1 \cdot 0$.

The findings for specific malformations within the broad anatomical groups are of particular interest. Among the malformations of the central nervous system, the specific conditions which were more frequent in twins than singletons were anencephaly $(p<0.00001)$ and hydrocephalus $(\mathrm{p}<0.001)$, the malformation ratios being 3.5 and $2 \cdot 0$ respectively. The rates of spina bifida, microcephaly, and encephalocele did not differ significantly in twins and singletons. The prevalence rate of anencephaly has been declining since the early 1970 s. $^{10}$ To investigate whether the trends were similar in singletons and twins, annual rates were examined (table III). Anencephaly rates were consistently higher in twins than singleton for each calendar year although the number of twins with anencephaly born each year is small. The rates declined over time in both groups until 1983. Since 1984 the rates in singletons have continued to fall but have increased in twins.

The specific malformations of the alimentary system which were higher in twins than singletons were tracheo-oesophageal fistula, eosophageal atresia and stenosis (malformation ratio $=1.9$, $\mathrm{p}<0.05$ ); atresia or stenosis of large intestine, rectum or anal canal (malformation ratio $=1.9$, $\mathrm{p}<0.001)$; and other or unspecified anomalies of the alimentary system (malformation ratio $=2 \cdot 1$, $\mathrm{p}<0.0001$ ). The most common diagnosis within the latter "unspecified" group was atresia or stenosis of the small intestine. The rate of cleft lip and/or palate was similar in twins and singletons.

Overall, malformations of the cardiovascular system were significantly more frequent in twins than in singletons. Of the specific diagnoses studied, the conditions for which there was a significant excess were patent ductus arteriosus (malformation ratio $=3.4, \mathrm{p}<0.0001$ ), and anomalies of the umbilical vessels (malformation ratio $=1.86, p<0.05$ ). There were also significant excesses of non-specific diagnosis of "cardiac murmur" (malformation ratio $=1.6, \mathrm{p}<0.01$ ) and of other or unspecified anomalies of the cardiovascular system (malformation ratio $=1 \cdot 7$, $\mathrm{p}<0.01$ ).

Of the malformations of the urogenital system, a highly significant excess of indeterminate sex or pseudohermaphroditism was found in twins (malformation ratio $=3.7, \quad \mathrm{p}<0.00001$ ). In contrast, other anomalies of the male external genitalia were significantly less frequent in twins than singletons (malformation ratio $=0.6$, $\mathrm{p}<0.0001)$. This group of anomalies includes undescended testis and congenital hydrocele. The rate for other or unspecified anomalies of the urogenital system was significantly higher in twins than in singletons (malformation ratio $=1.7$, $\mathrm{p}<0.05)$, the most common diagnosis within this group being obstructive defects of the renal pelvis and urethra.

Of the limb, musculoskeletal, and skin defects, polydactyly and syndactyly (malformation ratio $=0.8, p<0.01)$ and congenital dislocation of the hip (malformation ratio $=0.5, p<0.00001$ ) were less common in twins than in singletons. Exomphalos was more frequent in twins (malformation ratio $=2 \cdot 2, \mathrm{p}<0.0001$ ), along with other or unspecified anomalies of the musculoskeletal system (malformation ratio $=2 \cdot 3$, $\mathrm{p}<0.05$ ). Anomalies of the tongue, branchial cleft, and auricular sinus were less common in twins than in singletons (malformation ratio $=0.4$, $\mathrm{p}<0.01$ ), the most frequent diagnosis within this group being tongue tie. Post-anal dimple (malformation ratio $=0.4, \mathrm{p}<0.00001$ ), and other or unspecified anomalies of the skin or integument including birthmark and skin tag, were also less frequent in twins than in singletons (malformation ratio $=0.4, p<0.00001$ ). 
Table II Congenital malformation rates and malformation ratios in twins and singletons per 10000 births in England and Wales, $1979-80$ and 1982-85. (Twin rates and ratios are standardised for maternal age; numbers of malformations in parentheses.)

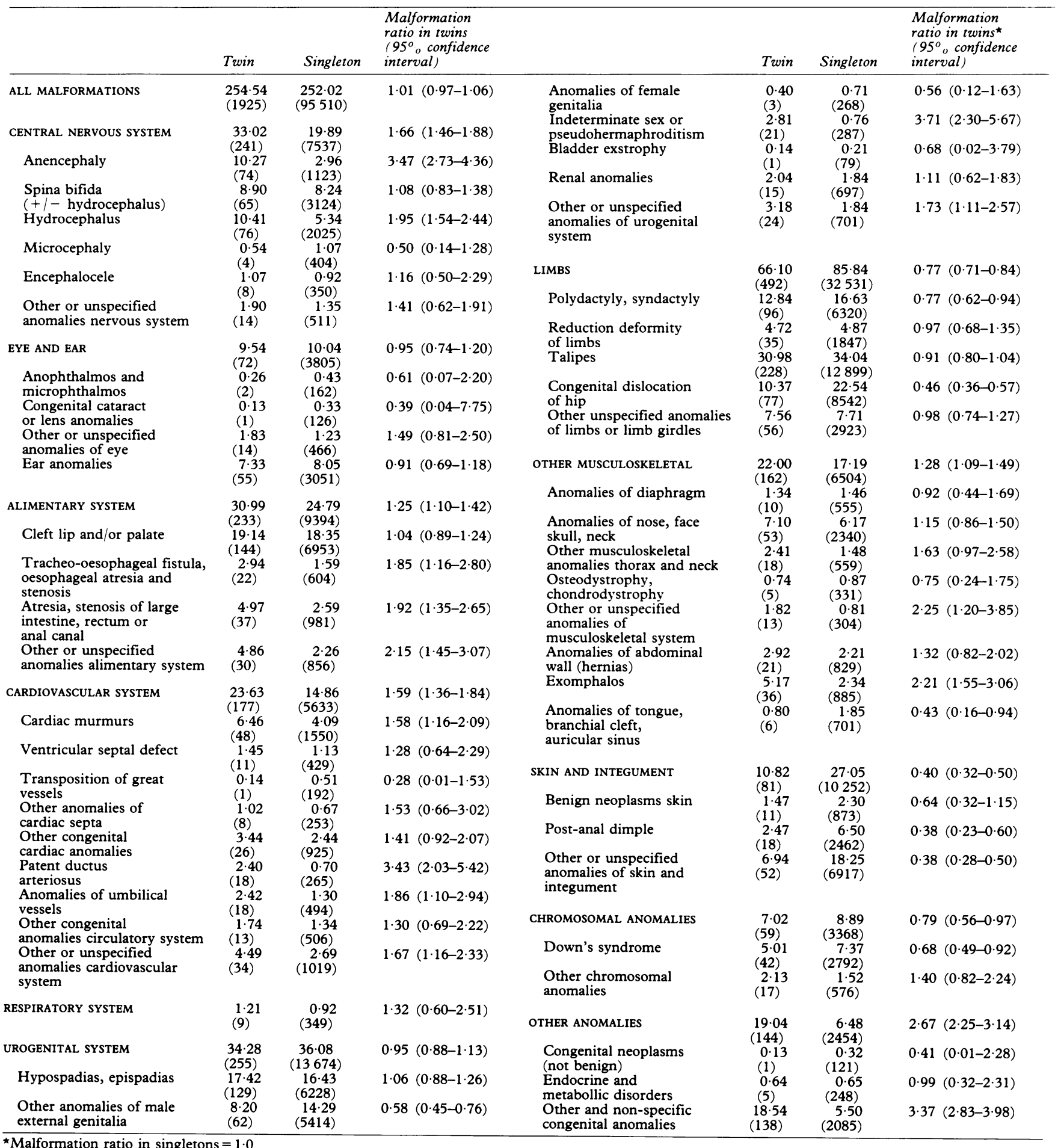

Table III Rates of anencephaly in twins and singletons per 10000 births, by year (rates and ratios are standardised by maternal age)
The rate of Down's syndrome was lower in twins than in singletons (malformation ratio $=0.7$, $\mathrm{p}<0.01)$. Lastly, other and unspecified congenital anomalies were highly significantly more frequent in twins than in singletons

\begin{tabular}{llll}
\hline & $\begin{array}{l}\text { Twin } \\
\text { rate }(\boldsymbol{n})\end{array}$ & $\begin{array}{l}\text { Singleton } \\
\text { rate }(\boldsymbol{n})\end{array}$ & $\begin{array}{l}\text { Malformation } \\
\text { ratio } \\
\left(95^{\circ} \text { o confidence }\right. \\
\text { interval) }\end{array}$ \\
\hline 1979 & $19.4(23)$ & $6.8(427)$ & $2.9(1 \cdot 8-4 \cdot 3)$ \\
1980 & $16.0(19)$ & $4.9(318)$ & $3.3(2 \cdot 0-9 \cdot 1)$ \\
1982 & $7.5(9)$ & $2.4(146)$ & $3.2(1 \cdot 4-6.0)$ \\
1983 & $4.2(5)$ & $1.7(108)$ & $2.4(0 \cdot 8-5 \cdot 7)$ \\
1984 & $6.8(8)$ & $1.2(77)$ & $5.6(2 \cdot 4-11 \cdot 0)$ \\
1985 & $8.4(10)$ & $0.7(47)$ & $11.5(5 \cdot 5-21 \cdot 1)$ \\
\hline
\end{tabular}

(malformation ratio $=3.4, \mathrm{p}<0.00001$ ). This category includes conjoined twins $(2 \%$ of all the twin malformations) and monster or multiple anomalies $(2 \%$ of twin malformations and $1 \%$ of singleton malformations).

\section{Discussion}

Data on the occurrence of malformations in more than 75000 twins born in England and Wales over a six year period are presented here. This data set is of similar size to that reported by Hay and Wehrung, ${ }^{3}$ who used information recorded on birth certificates from certain areas of the United 
States from 1962-65 to obtain data about malformations in twins. Other studies which have reported on malformations in twins included fewer subjects: 1200 twins from in the US Collaborative Perinatal Project; ${ }^{4} 4500$ twins born in Atlanta from 1969-76; 17000 twins born in Los Angeles from $1966-72 ;^{6} 15000$ twins born in Norway from $1967-69 ;^{7}$ and 15000 twins born in Sweden from 1973-81.9

The data presented here are derived from the OPCS congenital malformation notification scheme and, in common with all but three of the other studies, 588 only include malformations present at birth or observed within the first week of life. As a result, conditions which are not manifested until older ages, especially renal and cardiovascular anomalies, may be missed. Furthermore, the OPCS data collecting system is voluntary, and the completeness of reporting of anomalies varies. In one series the reporting of defects visible at birth, such as cleft lip, was $84 \%$ complete but only $34 \%$ of cardiovascular defects were reported. ${ }^{14}$ While underreporting is a problem for estimating prevalence rates in a population, comparisons of singletons and twins are biased only if there is differential reporting according to multiplicity. Some minor defects are relatively underascertained in twins, perhaps because twins are often of low birth weight and premature, and concern about their general well being could result in minor anomalies not being noted or recorded. ${ }^{37915}$ There is no evidence however that major malformations are relatively overascertained in twins. Another shortcoming of these data is that the sex of the cotwin was not recorded. It is therefore not possible to compare malformation ratio data in like sexed and opposite sexed twins.

In general, the findings here are consistent with those reported by Hay and Wehrung ${ }^{3}$ and by other authors, ${ }^{4-9}$ but the range of specific abnormalities studied and the number of cases of

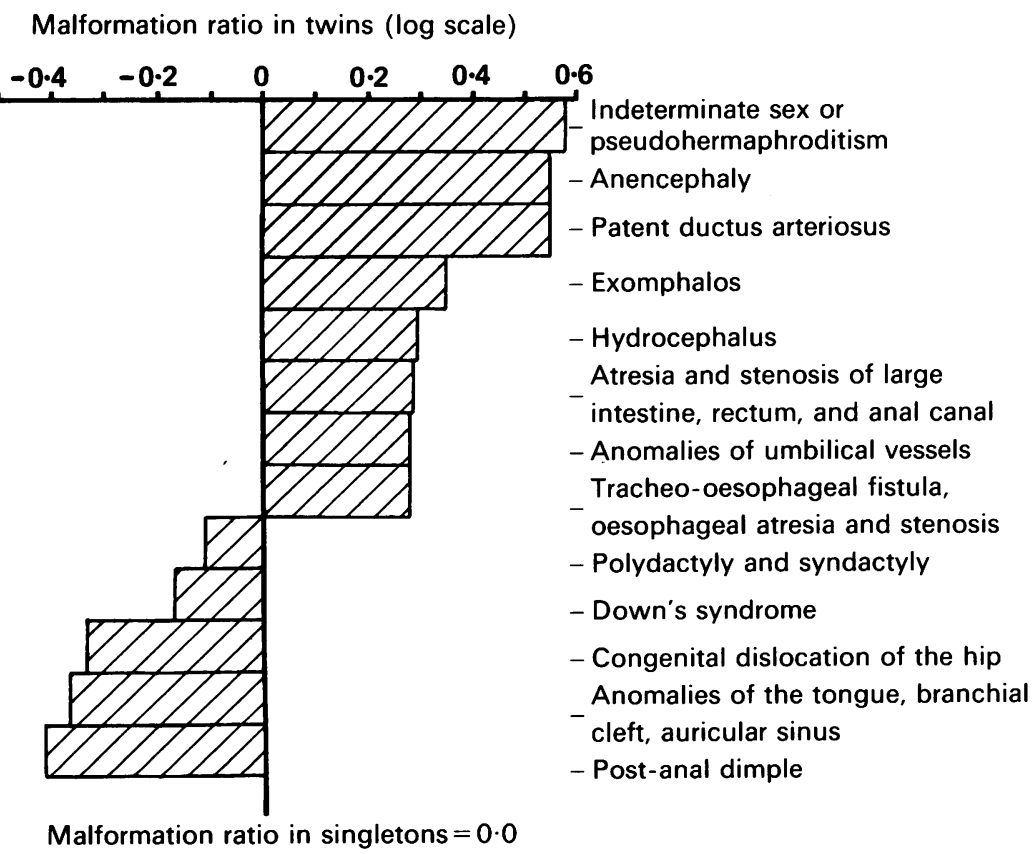

Specific malformations for which the malformation rates in twins and singletons differ significantly each specific malformation is greater here than in other studies. Eight specific malformations were found here to be significantly raised in twins compared to singletons (Figure). Five of these have been reported by others: the excess of anencephaly, hydrocephalus, tracheooesophageal and other intestinal fistulas, atresias or stenoses, and patent ductus arteriosus. ${ }^{3-9}$ Only one study did not find an excess of anencephaly, but this was probably because stillbirths had been excluded from the data analysed ${ }^{6} 9$ and in another, anencephaly was only $10^{\circ}{ }_{0}$ higher in twins. ${ }^{16}$

Table III indicates a fall in the rate of anencephaly in singletons between 1979 and 1985, due at least in part to antenatal screening followed by termination of pregnancy. The corresponding trend in twins is not so marked, which may indicate a reluctance to terminate an affected twin if a normal fetus is also present. The rise in rate of anencephaly in twins since 1984 could be a chance finding since the number of cases is small, but it is consistent with the suggestion of Windham and Sever that the association between twinning and anencephaly might be most marked when the prevalence of anencephaly is low. ${ }^{6}$

The excess of hydocephalus and of patent ductus arteriosus has been attributed to the high rate of prematurity among twins, since twins have a higher prevalence of preterm delivery and lower birthweight than singletons. ${ }^{12}$ This may not explain all the excess, however, since it persists even when restricting the analysis to births of more than 2500 g. ${ }^{9}$ Several authors noted that anencephaly was more frequent in like sexed twins ${ }^{3} 679$ but we have no relevant data.

Three of the conditions which were found to be significantly more common in twins than singletons have not been reported before: the excesses of indeterminate sex or pseudohermaphroditism; of exomphalos; and of anomalies of the umbilical vessels. The latter two may be related to the high rate of prematurity in twins. The relative excess of indeterminate sex or pseudohemaphroditism is the largest found here for any single condition. The only other published data on the frequency of these malformations in twins comes from Sweden ${ }^{9}$ where three cases were reported among twins but only $0 \cdot 3$ were expected on the basis of the rates in singletons. In cattle and other animals it is well recognised that a female cotwin of a male may be born as a sterile intersex. ${ }^{17}$

The condition, known as freemartinism, is thought to be the result of male hormones reaching the female through placental anastomoses, causing masculinisation. It is believed that the human equivalent of freemartinism does not occur, but our observation of an almost fourfold excess of indeterminate sex and pseudohermaphroditism in twins compared to singletons suggest that it might. The condition does not occur often, however. Only three out of every 10000 twins are affected.

Five specific anomalies were significantly less frequent in twin than singleton births (see figure). Compared to the anomalies which were more common in twins, four of these are of a relatively minor nature. The category "congenital 
dislocation of the hip" includes clicky hips, and "anomalies of the tongue, branchial cleft and auricular sinus" includes tongue tie. Similar deficits of the more minor malformations in twins have been reported by others, and it has been suggested that it may be due to biased ascertainment. $^{3} 79$

One exception is Down's syndrome. A lower rate of Down's in twins than in singletons has been reported previously. ${ }^{39}$ A possible explanation for this is that one or both members of a twin pair with Down's syndrome is more likely to die in utero than is a singleton with Down's syndrome.

Even though this study, and that of Hay Wehrung, ${ }^{3}$ is based on comparatively large populations of twins, the number of twins with any one specific deficit is often still small. These studies therefore lack power to detect differences in conditions of low prevalence. Spina bifida is, however, not as rare as many other malformations and no excess was observed in twins even though relatively large numbers of cases were reported. The narrow confidence interval around the malformation ratio for spina bifida, with an upper limit of 1.38 , suggests that if there is any difference in the rates of spina bifida between twins and singletons, it is small. Furthermore, other studies have reported no difference in the rates of spina bifida in twins and singletons. ${ }^{3}$ 5-7 9 The contrast between the findings for spina bifida and anencephaly is noteworthy especially since these two malformations share many risk factors and often occur together.

The deficits in the reported frequency of several common minor malformations in twins were counterbalanced by the significant excesses in other, more major anomalies, making the total reported malformation rate similar in twins and singletons (table I). Although some minor malformations may be underascertained in twins, it is unlikely that the excess of the major anomalies are due to overascertainment.

Further evidence that the excesses are unlikely to be artefacts is that they are not spread broadly over all types of malformations but are found for specific, generally well defined, conditions. Anomalies associated with prematurity such as patent ductus arteriosus, hydrocephalus, and exomphalos are increased in twins, and at least a part of the increase is due to prematurity and/or low birth weight.

But explanations for many of the findings are lacking - most of all why anencephaly, but not spina bifida, is more common in twins than singletons. The value of these data would have been enhanced had it been possible to study zygosity as well, and we suggest that in future the sex of the cotwin be included as part of form SD 56 on the OPCS notification scheme.

Information on the rates of congenital abnormalities in twins is important, not only for providing clues about aetiology of malformations, but also for interpreting findings on malformation rates in births resulting from assisted conception, such as in vitro fertilisation, many of which are twins or higher order births. ${ }^{18}$ National data of the type described here, despite their shortcomings, are clearly useful for this purpose.
Appendix

\begin{tabular}{l}
$\begin{array}{l}\text { Appendix } \\
\text { Malformation } \\
\text { equivalents } \\
\text { Condition }\end{array}$ \\
\hline
\end{tabular}

CENTRAL NERVOUS SYSTEM

Anencephaly 740

Spina bifida (with or without hydrocephalus) 741

Hydrocephalus 7423

Microcephaly $\quad 7421$

Encephalocele $\quad \mathbf{7 4 2 0}$

Other or unspecified anomalies of the nervous system

$320-359,7422,7424,7425$ $7428,7429,7676$

EAR AND EYE

Anophthalmos,

microphthalmos

Congenital cataract and

lens anomalies

7430,7431

Other or unspecified

anomalies of the eye

Ear anomalies

$360-379,7432,7434-7436$

7438,7439

380-389, 7440-7443

ALIMENTARY SYSTEM

Cleft lip and/or cleft palate

Tracheo-oesophageal

fistula, oesophageal

atresia and stenosis

Atresia and stenosis of

large intestine, rectum

and anal canal

$7490-7492$

Other or unspecified

anomalies of the

alimentary system

530-579 (except 550-553)

7504, 7505, 7507-7511

7513-7519

CARDIOVASCULAR SYSTEM

Cardiac murmurs

4253, 7852

Ventricular septal defects 7454

Transposition of the great

vessels

Other anomalies of cardiac

septa

745 (except 7454 and 7451)

Other congenital cardiac

anomalies

Patent ductus arteriosus

Anomalies of umbilical

vessels

7470

Other congenital

anomalies of the

circulatory system

Other or unspecified anomalies of the cardiovascular system

$$
7475
$$

747 (except 7470, 7475 and 7479 )

390-459 (except 4253), 7469,7479

RESPIRATORY SYSTEM

Anomalies of the respiratory system

490-519, 748

(except 7480, 7481)

UROGENITAL SYSTEM

Hypospadias, epispadias 7526

Other anomalies of the

male external genitalia

Anomalies of the female genitalia

$7525,7528,7786$

Indeterminate sex and

pseudohermaphroditism 7527

Bladder exstrophy $\quad 7535$

Renal anomalies 7530, 7531, 7533

Other or unspecified

anomalies of the

urogenital system

$580-608,614-629,7529$, 7532, 7534, 7536-7539 
LIMBS

Polydactyly or syndactyly 7550,7551

Reduction deformities of the limbs

$7552-7554$

Talipes $7545-7547$

Congenital dislocation of the hip

Other or unspecified anomalies of the limbs girdles

7544, 7555, 7556, 7558, 7559

OTHER MUSCULOSKELETAL

Anomalies of the diaphragm

7506, 7566

Anomalies of the nose face, skull, and neck

Other musculoskeletal anomalies of the thorax and neck

Osteodystrophy or chondrodystrophy

Other or unspecified anomalies of the musculoskeletal system 710-739, 7548, 7568, 7569

Anomalies of the abdominal wall (hernias) 5509, 5530-5532, 5538, 5539

Exomphalos

7567

Anomalies of the tongue, branchial cleft and auricular sinus $527-529,7444,7500-7502$

SKIN AND INTEGUMENT

Benign neoplasms of the skin

Post-anal dimple

Other or unspecified anomalies of the skin or integument

216,228

685

$520-523,5243,525$, 610-611, 680-709 (except 685), 757

CHROMOSOMAL ANOMALIES

Down's syndrome

Other chromosomal

anomalies

7580

7581-7589
OTHER ANOMALIES

Congenital neoplasms

(other than benign skin) 140-239 (except 216-228)

Endocrine and metabolic

disorders

$240-289$

Other or unspecified

congenital malformations $0-139,290-319,630-676$ 759, 760-779 (except 7675-7677, 7786), 780-799 (except 7852)

1 Botting B, MacDonald Davies I, MacFarlane A. Recen trends in the incidence of multiple births and associated mortality. Arch Dis Child 1987; 62: 941-50.

2 Alberman E. Multiple births. $\mathrm{Br}$ Med f 1988; 285: 510.

3 Hay S, Wehrung DA. Congenital malformations in twins. Am f Hum Genet 1970; 22: 662-78.

4 Myrianthopoulos NC. Congenital malformations in twins. Acta Genet Med Gemellol 1976; 25: 331-5.

5 Layde PM, Erickson JD, Falek A, McCarthy BJ. Congenital malformations in twins. Am $\mathcal{F}$ Hum Genet 1980 ; 32. 69-78. Windham GC, Sever LE. Neural tube defects among twin births. Am F Hum Genet 1982; 34: 988-98.

7 Windham GC, Bjerkedal T. Malformations in twins and their siblings, Norway, 1967-1979. Acta Genet Med Gemellol 1984; 33: 87-95.

8 Burn J and Corney G. Congenital heart defects and twinning. Acta Genet Med Gemellol 1984; 33: 61-9.

9 Kallen B. Congenital malformations in twins: a population study. Acta Genet Med Genellol 1986; 35: 167-78.

10 OPCS. Congenital malformation statistics notifications, 1971 1980. Series MB3 No 1. London: OPCS, 1983.

11 OPCS. Notification of congenital malformation scheme. Submission and processing of notification forms, (2nd ed) London: OPCS, 1983.

12 World Health Organization. Manual of the international statistical classification of disease. Injuries and causes of death. Ninth Revision. Geneva: WHO, 1975.

13 Breslow NE, Day NE. Stastistical methods in cancer research vol 2, The design and analysis of cohort studies. Lyon: IARC Scientific Publications No 22, 1986.

14 Knox EG, Armstrong EH, Lancashire R. The quality of notification of congenital malformations. 7 Epidemio Community Health 1984; 38: 296-305.

15 Swerdlow AJ, Melzer D. The value of England and Wales congenital malformation notification scheme data for epidemiology: male Community Health 1988; 42: 8-13.

16 Elwood JM, Elwood JH. Epidemiology of anencephelus and spina bifida. Oxford: Oxford University Press, 1980.

17 Nicholas FW. Veterinary genetics. Oxford: Oxford Science Publications, Clarendon Press, 1987.

18 Lancaster PA. Congenital malformations after in-vitro fertilization. Lancet 1988; ii: 1392. 